\title{
Effects of a simple educational intervention in well-baby clinics on women's knowledge about and intake of folic acid supplements in the periconceptional period: a controlled trial
}

\author{
Denhard J de Smit ${ }^{1, *}$, Stephanie S Weinreich ${ }^{2}$ and Martina C Cornel ${ }^{2}$ \\ 'MediClara Projects, PO Box 44, 1390 AA Abcoude, The Netherlands: ${ }^{2}$ Clinical Genetics/EMGO Institute for \\ Health and Care Research, VU University Medical Center, Amsterdam, The Netherlands
}

Submitted 11 October 2013: Final revision received 8 April 2014: Accepted 17 April 2014: First published online 27 May 2014

\begin{abstract}
Objective: To test the hypothesis that a concise intervention to promote the preconception use of folic acid (FA) supplements among mothers who visit a wellbaby clinic (WBC) for the 6-month check-up of their youngest child is effective. Effectiveness was measured as intention to use or actual use of FA supplements before a next pregnancy among women who expected to be pregnant within 0-12 months.

Design: Controlled intervention study with independent samples of intervention and control mothers. The intervention took place at the 6-month visit. A postintervention measurement was done in the intervention group and a comparable measurement in the control group at the 11-month check-up visit.

Setting: The intervention, verbal and in writing, was implemented in four Dutch WBC and given by the WBC physician to the mothers who visited the WBC.

Subjects: All mothers visiting the WBC were eligible for inclusion, unless they were unable to complete a questionnaire. The intervention group consisted of 198 (68\%) mothers recruited from 291 6-month intervention visits and the control group of 215 ( $84 \%$ ) mothers recruited from 255 11-month normal visits.

Results: In mothers who expected to be pregnant within 0-12 months, the proportion using or intending to use FA was $65 \%$ in the intervention group ( $n$ 49) $v .42 \%$ in the control group ( $n 43$; difference $23 \%, 95 \%$ CI $4,43 \%, P<0.05$ ).

Conclusions: Health education intervention at the 6-month WBC visit is an effective means to promote the use of FA supplements or the intention to do so.
\end{abstract}

\author{
Keywords \\ Health promotion \\ Folic acid supplements \\ Preconception care
}

More than 20 years ago it was proved that the intake of folic acid (FA) in the periconceptional period protects against neural tube defects (NTD). In many countries policy was developed to increase FA intake, including the advice to use FA supplements before conception, and to fortify staple foods. Nine years after the first one-off mass media campaign in the Netherlands in 1994, which was followed by a number of smaller initiatives mainly directed to supposed intermediaries like general practitioners, midwives and obstetricians/gynaecologists ${ }^{(1)}$, the percentage of women using FA in the periconceptional period had increased to approximately $43 \%$ in $2003^{(2)}$. The Dutch Ministry of Health decided in 2004 to allocate funds for the development and implementation of additional strategies to achieve a $70 \%$ adequate FA intake by 2010 . The focus was on the development and implementation of interventions and channels through which the target group of women who would become pregnant could be educated effectively and in time. Two channels were identified as specifically appropriate: community pharmacies and wellbaby clinics (WBC). Through these channels it would be possible to deliver information and advice by so-called 'important others', in this case highly appreciated medical professionals, who are part of the social influence, one of the determinants of behavioural intentions in the ASE model $^{(3)}$. Community pharmacies had started in 2004 already with a large-scale distribution of stickers and small leaflets together with the delivery of oral contraceptives ${ }^{(4)}$. Part of the ongoing implementation was made possible with grants from the Ministry of Health and this contributed to the further growth of FA intake to $50 \%$ in $2005^{(5)}$. There was no documented experience with FA intervention in the WBC channel at that time, and therefore development and evaluation were needed to assess the potential value of this channel.

The WBC channel is potentially useful for an FA intervention to benefit children born second or higher in rank. This group forms about half of all newborns in the 
Netherlands. The WBC for 0-4-year-olds have a very high attendance rate (>95\%) and thus almost half of mothersto-be visit these centres several times in a face-to-face setting with either a physician or a nurse, before a next pregnancy. The first contact between the youth healthcare organisation and newborns and their parents consists of a home visit, when a heel prick test is done and information about the pregnancy history and the neonate is collected. After this, mothers/fathers and children visit the WBC according to a fixed scheme, for vaccinations and advice. For example, standard visits are scheduled for children aged 6 and 11 months. These encounters offer a good opportunity to provide those women with information and advice regarding preparations for a next pregnancy. The average time to next pregnancy is about 2.5 years $^{(6)}$. One of the topics that could be addressed is the timely intake of FA supplements before the next pregnancy. In the present study we address the following research questions: (i) is it feasible to incorporate education about FA prevention in the daily routines of the WBC and (ii) if so, will the intervention have an effect on (predictors of) FA intake?

An intervention was developed through collaboration between the researchers and the staff of three WBC using the 'reflect-plan-act-observe' $\operatorname{method}^{(7)}$ (see Methods). This action research method was chosen to secure optimal feasibility of the implementation of the intervention in the practical situation of the WBC context.

The main objective of the study reported here was to see whether this intervention leads to a meaningful rise in intention to use, or actual use of, FA in women who can be targeted through WBC.

In the Netherlands the general advice is to take FA supplements from at least four weeks before planned conception onwards, which is different from the advice given in e.g. the USA to take those supplements throughout childbearing age. The adherence to the Dutch advice can thus only be meaningfully evaluated in women with actual pregnancy plans and attempts or those who are already pregnant. Preconception FA intake is often measured using retrospective assessment during prenatal visits, but this has several methodological drawbacks. The effect of interventions to promote FA supplement use is best measured in women who might become pregnant at any time ('loosely planned') or who are actively trying to become so. To capture enough of these women in an intervention study would imply the inclusion of relatively large numbers. We chose an alternative approach based on the earlier finding that, in line with general education theories, knowledge and behavioural intentions concerning the use of FA supplements are positively related to the personal expectation of the duration to a pregnancy (labelled by us as 'expected time to pregnancy' or e-TTP). This relationship is clearly seen from an expectation of 12 months or less ${ }^{(8)}$. We therefore assume that at 12 months e-TTP some women are already open to interventions directed at changes in knowledge and attitude. The effect of interventions could thus be meaningfully measured in the group with an e-TTP of 12 months or less.

The objective of the study was operationalized into the following hypothesis: information given in the personal encounter with the WBC physician during the visit for a 6-month-old child leads, among the mothers who expect to be pregnant again within 12 months, to an increase of at least $15 \%$ in intention to use, or the actual use of, FA five months later. A secondary objective of the study was to assess the effect of the intervention on intention to use, or the actual use of, FA among mothers with a later e-TTP, between 12 and 24 months. A third objective was derived from social psychology theories (like the ASE model) which posit that intention and action are driven by knowledge and attitude ${ }^{(3,9)}$. In order to better understand the potential utility of the intervention, the study therefore also explored its effect on knowledge about and attitudes towards the use of FA.

\section{Methods}

\section{Design}

Four pilot WBC developed the intervention for implementation with the reflect-plan-observe method as described below. Later, the intervention was implemented simultaneously in four other WBC. A controlled trial was performed in these WBC, comparing mothers who received the intervention at the 6-month visit (outcome measured at the 11-month visit) with a control group of mothers whose 6-month visit had taken place prior to implementation of the intervention (outcome measured at the 11-month visit). A flowchart of the study population is shown in Table 1.

\section{Setting and study size}

The study was originally designed to include at least about 340 respondents with an e-TTP of 0-12 months to be able to detect changes in outcome variables of at least $15 \%$ (power $=0.80$ and $\alpha=0.05$ ). This would require the inclusion of 600 or more women for which the cooperation of at least eight WBC was needed; however, only four were found willing to participate.

The study participants were collected at four WBC in towns A (three) and B (one) in the eastern part of the Netherlands. Preparation for implementation took place from May 2006 to June 2007. The controlled trial ran simultaneously in all WBC from the second half of 2007 through the first half of 2008 .

\section{Participants}

All mothers visiting the WBC were eligible for inclusion, unless they would be unable to complete a questionnaire due to lack of sufficient language skills. The criteria applied for inclusion in the intervention group were: (i) the mother herself attended the 6-month and 11-month 
Table 1 Scheme of the study design

\begin{tabular}{|c|c|c|c|c|}
\hline \multicolumn{2}{|c|}{ INTERVENTION } & \multirow[b]{2}{*}{ Stage } & \multicolumn{2}{|l|}{ CONTROL } \\
\hline Study period & & & & Study period \\
\hline $\begin{array}{l}\text { Month 1-5 } \\
\text { Month 6-10 }\end{array}$ & $\begin{array}{l}\text { Scheduled 6-month visits ( } n \text { 291) } \\
\text { Confirmed presence at 11-month visit ( } n \text { 215) } \\
\text { Mothers included ( } n \text { 198) } \\
\text { Questionnaire response ( } n \text { 185) } \\
\text { Maximum number for analysis ( } n \text { 185) } \\
\text { Pregnant }(n 14) \\
\text { e-TTP }=0-12 \text { months }(n 50) \\
\text { e-TTP }=12-24 \text { months }(n 17) \\
\text { e-TTP }>24 \text { months }(n 104)\end{array}$ & $\begin{array}{l}\text { Allocation } \\
\text { Follow-up } \\
\text { Analysis }\end{array}$ & $\begin{array}{l}\text { Scheduled 11-month visits ( } n \text { 255) } \\
\text { Confirmed presence at 11-month visit ( } n \text { 228) } \\
\text { Mothers included ( } n \text { 215) } \\
\text { Questionnaire response ( } n \text { 190) } \\
\text { Maximum number for analysis ( } n \text { 190) } \\
\text { Pregnant }(n \text { 10) } \\
\text { e-TTP }=0-12 \text { months }(n \text { 45) } \\
\text { e-TTP }=12-24 \text { months }(n \text { 23) } \\
\text { e-TTP }>24 \text { months }(n 112)\end{array}$ & Month 6-10 \\
\hline
\end{tabular}

e-TTP, expected time to pregnancy.

visit and (ii) was able to and consented to fill in a questionnaire. Criteria applied for inclusion in the control group were: (i) the mother herself attended the 11-month visit and (ii) was able to and consented to fill in a questionnaire. (Due to limitations in patient files, it was not always possible to retrospectively confirm whether or not a mother in the control group had attended the 6-month visit. Therefore only women for whom absence at the 6-month visit had been recorded explicitly were excluded from the control group.) A WBC staff assistant registered all scheduled visits of children, whether or not the mothers attended the visit, whether they were eligible and whether they were invited for the study.

\section{Intervention: development and application}

The intervention was developed in cooperation between the staff of the pilot WBC and the researchers. The latter played a facilitating role towards the WBC staff. The intervention was developed and evaluated in three cycles of 'reflect-plan-act-observe, ${ }^{\text {(7) }}$. The staff decided that, at the postpartum home visit, a question on FA use would be asked and that the information had to be added to the patient file. The 6-month encounter was chosen as the most suitable moment to give further information for a possible next pregnancy and an information leaflet for mothers with an information guide for WBC physicians was developed. This complete intervention was implemented in these four WBC and process data were collected in two cycles in 222 and 203 patient contacts, respectively. The conclusion of the staff, based on the appraisal of both their own experience and the collected quantitative data, was that it was feasible to implement the intervention permanently in the WBC context and that they would recommend that other WBC teams implement it as well.

In the trial itself the collection of information about FA use at the home visit was not implemented, because it would increase the duration of the study by at least 6 months; therefore the information on prior FA use was only collected at the 6-month encounter.
The intervention as applied in the trial consisted of a tailored provision of information at the 'physician-mother and child' encounter at the 6-month visit. At the end of the encounter the physician was to inquire, by asking or by checking the patient file, about the FA intake compliance in the last pregnancy. Depending on the level of compliance, the physician would then:

1. in the case of adequate compliance, only confirm and encourage the adequate intake of FA;

2. in the case of inadequate compliance, give verbal information and information in writing on adequate FA intake.

The information in writing was a leaflet especially developed for the less-well educated, consisting of some iconic illustrations and short, easy-to-read texts comprising the core messages (see online supplementary material).

\section{Measures and scoring}

The outcome variables were collected with a questionnaire filled in by mothers attending the WBC for the 11-month visit.

Knowledge was measured in the same way as in comparable studies in the Netherlands ${ }^{(5)}$; briefly, respondents were asked in open questions to write down what they knew about the effect of folic acid and when they thought it should be used. Correct knowledge was scored as follows: 'knows prevention' if NTD or congenital anomalies were mentioned; 'knows period' if at least starting before pregnancy was mentioned; and 'knows correct period' if $\leq 4$ weeks before pregnancy until $\geq 8$ weeks of pregnancy was mentioned.

Attitude was addressed with two measures. The first one was a general single question, 'Would you recommend to women in your environment who want to become pregnant that they take extra folic acid?' (answer categories: 'Yes'/No'). The second measure was a newly developed Likert-scale consisting of six semantic contrast items on a five-point scale. The attitude statement was, 'I think that the use folic acid supplements if I myself want to become 
pregnant is...' The contrast items were: good - bad; important - unimportant; disquieting - reassuring; clever stupid; nice - annoying; detrimental - healthy.

The FA intake was assessed in the same way as in previous Dutch studies ${ }^{(5)}$, with the questions targeted to all pregnant respondents and respondents with an e-TTP of 24 months or less. For pregnant women the intake before and during the pregnancy was assessed (FA intake started before pregnancy and continued during pregnancy was scored as adequate ' 1 '; all others as inadequate ' 0 '). For non-pregnant women with an e-TTP of 24 months or less only current intake of FA was assessed and in the case of current non-intake, their intention to use FA was assessed (question: 'Do you use folic acid supplements now?'; answer options: 'Yes I do', 'No, but I intend to do so because...' and 'No, because...'). From these data the score 'FA use or intention' was computed as positive (one of the first two options was chosen) or negative (third option was chosen).

The co-variables were also measured in the questionnaire: gravidity (first, second, third or higher); pregnant or not; if not pregnant, the expected time to a next pregnancy (e-TTP; question: 'Do you hope or expect to become pregnant again within the coming $\mathrm{X}$ months?'; answer categories: 'Yes'/No' for $\mathrm{X}=0-3,3-6,6-12,12-24$ months). The pregnancy and e-TTP answers were combined to give the time to pregnancy (TTP) score (' 1 ' if pregnant to ' 6 ' if e-TTP $>24$ months). The questionnaire was also used to collect data on education (highest completed of: elementary school, lower vocational education, secondary school, secondary vocational education, high school, higher vocational education, scientific education). Levels of education were then grouped as low, middle and high, compliant with the CBS (Statistics Netherlands) and International Standard Classification of Education schemes ${ }^{(10)}$.

During the trial, physicians registered the intervention on a small form (A6) during or directly after completion of the 6-month visit. The following items were registered:

1. attention paid to FA ('Yes'/'No') and if not, reason why (lack of time/communication not sufficiently possible/ forgotten/other, namely...);

2. FA use in last pregnancy known ('Yes'/No');

3. FA use in last pregnancy adequacy (adequate/started too late/stopped too early/inadequate otherwise/not at all);

4. FA education given ('Yes'/No') and if yes, how verbally (none/confirmation/complete explanation/other) and how in writing (none/intervention leaflet/other).

From these answers scores were computed for:

1. information given ('Yes' if any information given verbally or in writing/'No' in all other instances);

2. verbal and written information given ('Yes' if both/'No' if only one of both);

3. verbal or written information given ('Yes' if only one of these/'No' if both).

\section{Data collection and handling}

Questionnaires were handed out and collected at the WBC during the 11-month visit. Women were however allowed to take the questionnaire home and to return it by mail.

Questionnaire analysis was done by two persons (independently; D.J.d.S. and a Master's level medical student). All data were entered manually with data entry software and analysed in the statistical software package IBM SPSS Statistics 20.

\section{Efforts to address bias}

Control and intervention mothers were included from the same WBC to have comparable exposure to other sources of information about FA like general practitioners, midwives or obstetricians/gynaecologists that might vary among different locations. Measurements of outcome variables all took place at the 11-month visit to have comparable exposure to the 'WBC environment' for control and intervention mothers. During the study period the WBC did not implement broader FA education, e.g. by using posters in the waiting room, to keep the exposure contrast between control and intervention mothers maximal. Multivariate analysis was done for the main outcome measure to adjust for confounding.

\section{Analysis}

The distribution of continuous and ordinal co-variables was tested for normality with the Shapiro-Wilk test; nonnormally distributed variables $(P>0 \cdot 01)$ were compared with the Mann-Whitney $U$ test, otherwise the independent $t$ test was used. The effect of the intervention was assessed for binary outcome variables with the $\chi^{2}$ test and for continuous outcome variables with the independentsamples $t$ test or the Mann-Whitney $U$ test, if not normally distributed (Shapiro-Wilk). For the outcome measures 'FA use or intention' and 'knows prevention and period', multiple logistic regression modelling was performed to control for possible confounding with the following variables entered in the model: age, gravidity, education, e-TTP and the WBC that the participant visited. Effect modification was not assessed. IBM SPSS Statistics 20 was used for these analyses. Two-tailed $P$ values below 0.05 were considered statistically significant. The $95 \%$ confidence intervals for differences in proportion of independent groups were calculated with the formula given by Altman ${ }^{(11)}$.

\section{Subgroups}

The control group of mothers was included at the 11-month visit and their attendance at the 6-month visit had to be retrieved from the patient records. In some cases these appeared not to contain adequate information on who accompanied the child at that visit. To evaluate the probability of a selection bias in the main analyses due to erroneous inclusion of control mothers who were not 
present at the 6-month visit, the outcomes 'knowledge' and 'attitude' were also analysed for the subgroup of control mothers who had confirmed attendance at the 6-month visit.

\section{Missing data}

Analyses are based on valid data available for each (set) of variables analysed. No missing data are imputed.

\section{Results}

\section{Inclusion, implementation of the intervention and questionnaire response}

The inclusion took place from October 2007 until March 2008. In total, 291 6-month (intervention) and 255 11-month (control) visits were planned at the WBC (total 546; Table 1). From these planned visits 198 (68\%) intervention mothers and 215 (84\%) control mothers were included in the study (total 413). Inclusion took place at the 11-month visit and required attendance of the mother. The presence of the mother at the 11-month visit was confirmed for 215 cases in the intervention arm and 228 in the control arm. Relative to these numbers inclusion was $93 \%$ and $94 \%$, respectively. The educational intervention was implemented in the intervention group as follows: no information given in $23 \%$ ( $n$ 46); verbal or written information given in $36 \%$ ( $n$ 71); verbal and written information given in $41 \%$ ( $n$ 80; $n 1$ missing). Thus some form of information was given to $77 \%$ of the intervention group. The overall questionnaire response was $91 \%(375 / 413)$, with $93 \%(185 / 198)$ in the intervention group and $88 \%(190 / 215)$ in the control group.

\section{Demograpbics}

The intervention and control group differed in age (average 31.7 years $(n$ 184) $v .32 .9$ years ( $n$ 190); Mann-Whitney $U$ test, $P<0.01)$ but not in number of years of education completed after elementary school (average 8.6 years ( $n$ 177) v. 8.1 years ( $n$ 183); Mann-Whitney $U$ test, NS), level of educational class (average $2 \cdot 4$ ( $n$ 181) v. $2 \cdot 3$ ( $n$ 185);
Mann-Whitney $U$ test, NS) or gravidity (1.7 ( $n$ 180) v. 1.9 ( $n$ 189); Mann-Whitney $U$ test, NS).

Within the subgroup of respondents with an e-TTP of 0-12 months, the distribution of none of these demographic variables was significantly different between the intervention and control groups (Mann-Whitney $U$ test, NS for all).

\section{Outcomes}

Folic acid use or intention to use

Out of 185 mothers in the control group and 190 in the intervention group, twenty-one were pregnant again at the time they filled out the questionnaire. Adequate FA intake among pregnant women was $50 \%$ in the intervention group $(6 / 12)$ and $55 \%$ in the control group (5/9; difference $-6 \%, 95 \% \mathrm{CI}-49,38 \% ; \chi^{2}$ test, NS).

In mothers with an e-TTP of 0-12 months, the proportion using or intending to use FA was $65 \%$ in the intervention group ( $n$ 49) $v .42 \%$ in the control group ( $n$ 43; difference $23 \%, 95 \%$ CI 4, $43 \%$; $\chi^{2}$ test, $P<0 \cdot 05$; see Table 2).

Table 2 also shows a more detailed breakdown of TTP intervals in mothers with an e-TTP up to 12 months. In both the intervention and control groups, intention to use (or use of) FA increased as TTP got shorter. In addition, Table 2 shows that in mothers with a later e-TTP of 12-24 months, the proportion using or intending to use FA was $6 \%$ in the intervention group ( $n$ 17) and $19 \%$ in the control group ( $n$ 21; difference $-13 \%$, 95\% CI - 33, $7 \% ; \chi^{2}$ test, NS).

The effect of the intervention on (intention to) use FA was also calculated as an odds ratio, to allow correction for possible confounders (WBC, education, gravidity, TTP score and age). For respondents with an e-TTP of 0-12 months, the adjusted OR for FA use or intention was 3.18 (95\% CI 1.01, 9.98; unadjusted $\mathrm{OR}=2 \cdot 61,95 \%$ CI $1 \cdot 12,6 \cdot 08)$.

\section{Knowledge}

Table 3 shows the scores for four knowledge outcomes in the intervention and control groups. In the main outcome

Table 2 Folic acid (FA) use or intention scores among respondents with an expected time to pregnancy (e-TTP) of $<24$ months by study group; controlled trial of an educational intervention conducted in well-baby clinics to promote preconception use of FA supplements, eastern part of the Netherlands, 2007-2008

\begin{tabular}{lccccc}
\hline & \multicolumn{5}{c}{ FA use or intention } \\
\cline { 2 - 5 } & \multicolumn{2}{c}{$\begin{array}{c}\text { Intervention group } \\
(n \text { 67) }\end{array}$} & & \multicolumn{2}{c}{$\begin{array}{c}\text { Control group } \\
(n \text { 68) }\end{array}$} \\
\cline { 2 - 5 } e-TTP & $\%$ & $n^{\prime}$ & $\%$ & $n^{\prime}$ & $\chi^{2} P$ \\
\hline $0-12$ months & 65 & 49 & 42 & 43 & $<0.05$ \\
0-3 months & 94 & 16 & 73 & 11 & NS \\
4-6 months & 67 & 15 & 70 & 10 & NS \\
7-12 months & 39 & 18 & 14 & 22 & NS \\
$12-24$ months & 6 & 17 & 19 & 21 & NS \\
\hline
\end{tabular}

$n$ is the total number of questionnaires returned. Analysis per variable is based on $n^{\prime}$, the number of respondents with data available for that variable. 
Table 3 Knowledge scores among all respondents and a subgroup with an expected time to pregnancy (e-TTP) of 0-12 months by study group; controlled trial of an educational intervention conducted in well-baby clinics to promote preconception use of FA supplements, eastern part of the Netherlands, 2007-2008

\begin{tabular}{|c|c|c|c|c|c|c|c|}
\hline \multirow[b]{3}{*}{ Knowledge variable } & \multicolumn{7}{|c|}{ Knowledge score } \\
\hline & \multicolumn{2}{|c|}{$\begin{array}{l}\text { Intervention } \\
\quad(n \text { 185) }\end{array}$} & \multicolumn{2}{|c|}{$\begin{array}{l}\text { Control } \\
(n 190)\end{array}$} & \multirow[b]{2}{*}{ Difference } & \multirow{2}{*}{$\begin{array}{l}95 \% \mathrm{Cl} \text { of } \\
\text { difference }\end{array}$} & \multirow[b]{2}{*}{$\chi^{2} P$} \\
\hline & $\%$ & $n / n^{\prime}$ & $\%$ & $n / n^{\prime}$ & & & \\
\hline Knows prevention (mentions prevention of NTD or CA) & 69 & $119 / 173$ & 55 & 95/174 & 14 & 4,24 & $<0.01$ \\
\hline Knows period (mentions at least start before pregnancy) & 86 & $159 / 184$ & 75 & $142 / 190$ & 11 & 4,20 & $<0.01$ \\
\hline Knows prevention and period & 65 & $111 / 172$ & 47 & $81 / 174$ & 18 & 8,28 & $<0.01$ \\
\hline $\begin{array}{l}\text { Knows prevention and period } \\
\text { e-TTP }=0-12 \text { months }\end{array}$ & 73 & $35 / 48$ & 49 & $22 / 45$ & 24 & 5,43 & $<0.05$ \\
\hline $\begin{array}{l}\text { Knows correct period ( } \leq 4 \text { weeks before pregnancy until } \geq 8 \text { weeks } \\
\text { of pregnancy) }\end{array}$ & 15 & $28 / 184$ & 5 & $10 / 190$ & 10 & 4,16 & $<0.01$ \\
\hline
\end{tabular}

NTD, neural tube defects; CA, congenital anomalies.

$n$ is the total number of questionnaires returned. Analysis per variable is based on $n^{\prime}$, the number of respondents with data available for that variable.

measure, the score for overall good knowledge ('knows prevention and period') was $18 \%$ higher in the intervention group and statistically significant $\left(\chi^{2}\right.$ test, $\left.P<0 \cdot 01\right)$. In the subgroup with e-TTP of $0-12$ months this measure was also significantly higher $\left(24 \% ; \chi^{2}\right.$ test, $\left.P<0.05\right)$ in the intervention group.

The adjusted OR (adjusted for WBC, education, gravidity, TTP score and age) for the variable knows prevention and period' was 2.35 (95\% CI 1.46, 3.79; unadjusted $\mathrm{OR}=2 \cdot 09 ; 95 \% \mathrm{CI} 1 \cdot 36,3 \cdot 22$ ), confirming the effect of the intervention. For respondents with an e-TTP of $0-12$ months the adjusted OR was $4 \cdot 1$ (95\% CI 1.5, 11.6; unadjusted $\mathrm{OR}=2 \cdot 8 ; 95 \% \mathrm{CI} 1 \cdot 2,6 \cdot 7)$.

\section{Attitude}

The reliability analysis of the Likert-scale measure yielded a Cronbachs' $\alpha$ of 0.81 , indicating good internal consistency. The overall average was 4.5 on a scale maximum of 6 . The scores in intervention ( $n$ 181) and control group ( $n$ 174) were equal: 4.5 (Mann-Whitney $U$ test, NS).

To the general single attitude question 'Would you recommend to women in your environment who want to become pregnant that they take extra folic acid? the answer was 'Yes' by $95 \%$ of respondents in the intervention group and by $91 \%$ in the control group (difference $4 \%, 95 \% \mathrm{CI}-1,10 \% ; \chi^{2}$ test, NS).

\section{Subgroup analyses}

The comparison of the intervention group with the control subgroup of only mothers who had confirmed presence at the 6-month visit ( $n$ 92) showed that the direction and size of the difference in the knowledge scores were comparable to those in the main analyses (difference for 'knows prevention and period' is $21 \%$; other data not shown). Both attitude scores were comparable (not shown). The FA use or intention score among respondents with e-TTP of $0-12$ months was positive in $65 \%(32 / 49)$ in the intervention group $v .42 \%(11 / 26)$ in the control subgroup.

\section{Discussion}

\section{Key results}

The present study shows that the FA education intervention carried out at the 6-month visit in WBC leads, among the group of all visitors, to an increase of $18 \%$ in correct knowledge of the prevention effect of FA and the need to start before pregnancy. Among women with an e-TTP of 0-12 months the intervention leads to an increase of $23 \%$ in the intention to use FA (or the actual use of FA) before pregnancy and a $24 \%$ increase in adequate knowledge. The intervention did not lead to a change in attitude towards the intake of FA supplements. The intervention was applied in $77 \%$ of the encounters and confirms the feasibility of this intervention in the WBC context, but also shows potential for further improvement of the effects on the target population. The overall conclusion is therefore that the WBC FA education intervention is an effective means to promote knowledge about periconceptional FA and the intention to use or actual use of FA supplements.

\section{Strengths and limitations}

The practically most relevant end point of FA education is the intake of FA supplements in relation to the periconception window. Questionnaires have been shown to have limited validity if used retrospectively ${ }^{(12)}$, e.g. at first prenatal visit. To our knowledge, the present study is one of the few that has assessed current intention and actual intake of FA use during the periconceptional window $^{(13,14)}$. It is to our knowledge the first documented use of a community-based intervention in WBC to improve FA use.

A requirement for inclusion was that the mothers were present at both the 6-month and 11-month visit. However, documentation of the mother's presence at 6 months was less rigorous for the control group than the intervention group (as described in 'Participants' subsection in the Methods). The control group in the primary analysis might 
thus comprise a number of mothers who did not in fact attend the 6-month visit. This might cause bias towards less 'exposure' to WBC influences in the control group compared with the intervention group. However, the analysis using the control subgroup with confirmed attendance at both visits showed differences in the same direction and of the same magnitude as the primary analysis. It seems valid therefore to attribute the differences observed to the intervention.

The method of inclusion implied that potential controls were identified at the 11-month visits whereas intervention participants were included at the 6-month visits. This might cause the intervention group to be 5 months (younger) in age, explaining part of the age difference of 1.2 years that was found. However it seems implausible that this difference would have impact on the validity of the findings.

The highest rate of missing values occurred in the control group ( $8 \%$ for both the Likert-scale attitude question and the question about knowledge of the purpose of FA supplementation). In the intervention group, missing rates for these questions were lower $(2 \%$ and $6 \%$, respectively). Taken together, missing rates were relatively modest and their effect on the differences in outcome measures was considered negligible.

\section{Interpretation}

The present study suggests an inverse relationship between e-TTP and behavioural intention to use FA. This is consistent with the expectation from explanatory social psychological models for the prediction of (information seeking) behaviour ${ }^{(3)}$.

Our study and its results can be placed in the full ASE model as follows. First, in the intervention group the 'social influence' towards the FA intake was planned to be strong, using the WBC physician in the role of 'important other'. Second, the intervention increased knowledge but did not change attitude towards intake. Third, in the intervention group, actual use or intention to use FA was increased. Information on self-efficacy is not available, but there was no deliberate action to improve this through the intervention. The constellation pictured implies that the change in actual use or intention to use FA is the result of increased knowledge and strengthened social influence. The lack of change in attitude could be caused either by the intervention not being effective or by a ceiling effect ( $\mathrm{a}$ score of 4.5 on scale of 6 may leave little room for improvement). The latter explanation and the contribution of increased knowledge match findings in other studies: that hardly any objections against use of FA supplements are found, but also that, although many women know something about FA supplements, especially knowledge on when to start taking FA supplements is relatively low ${ }^{(2)}$.

In the present study we did not test at the individual level for association between theoretical determinants of behaviour (knowledge, attitude) and intention or use of
FA. Our model interpretation is an ecological one and would need corroboration by studies with appropriate design.

The deployment of the face-to-face WBC intervention can be considered a worthy addition to mass media campaigns, both with respect to the scope of FA education and the opportunity to provide and check with the patient detailed information on how and when to use FA. The lack of proper knowledge was pointed at by Ray et al. as a cause of poor FA use despite awareness of its relevance $^{(15)}$. Furthermore, earlier studies showed that FA use in second and higher pregnancies is relatively low, so the present intervention targets a high-risk group ${ }^{(5)}$.

The estimated direct additional effect on the timely intake of FA is $3.7 \%$ or approximately 6500 pregnancies per year in the Netherlands (2012) and this would prevent 5.9 NTD cases per year. For this estimate we first calculated a number of 62571 mothers per year attending the 6month visit and who will be pregnant again using the following parameters: 176000 births/year; 55\% of all pregnancies are second or higher in rank; first-year attendance rate of WBC is $95 \%$ (also among migrant groups ${ }^{(16)}$ ); $68 \%$ of the attendees are mothers (set to inclusion - which required attendance of mother - rate of planned visits in the present study). Then we calculated an increase of 6489 women with timely intake based on: (i) an increased (intended) intake of $23 \%$ (difference in 'use or intending to use' in the present study) among those with e-TTP of 0-12 months; and (ii) of all mothers visiting the WBC who will become pregnant again in the future, $45 \%$ have an e-TTP of $0-12$ months (the quotient of ninety-three, which is the number of 0-12 months e-TTP in the present study, and $55 \% \times 375=206$, which is the expected number of women becoming pregnant again in the present study). Finally, we calculated 5.9 cases of NTD prevented based on an NTD prevalence among non-FA users of 1.4:1000 and the FA protection factor of $65 \%{ }^{(17)}$.

The intervention is also a worthy extension of the set of interventions that make use of a face-to-face encounter for the timely delivery of the message to the individual by health-care professionals like pharmacists ${ }^{(13)}$, family physicians $^{(18)}$ and midwives or obstetricians ${ }^{(19)}$.

\section{Recommendations}

The Dutch Ministry of Health previously set a target of $70 \%$ adequate FA intake. The results of our study show a significant increase of practical, relevant knowledge to $65 \%$ of the general population of WBC-visiting mothers and to $73 \%$ in the subgroup with an e-TTP of $0-12$ months. In the latter group also a significant increase to $65 \%$ in FA use or intention to use was found. These increases are additional to the pre-existing levels induced by mass media and other sources as well as the exposure to information during at least one pregnancy. The intervention is very short and simple but is nevertheless effective. Based on the above results, the known cost-saving/effectiveness of 
periconceptional FA prophylaxis and the relatively simplicity of the intervention, we strongly recommend its wider implementation.

\section{Acknowledgements}

Acknowledgements: The authors thank Dr Phillis Lakeman for her support in the initial training of WBC doctors and nurses, Mrs Sonja van de Koppel for her assistance in the data collection and data entry, and all of the doctors, nurses, assistants and visitors of the WBC who enabled the execution of this study. Financial support: This study was funded by the Task Force Folic Acid (2004-2007) of the Dutch Ministry of Health $(\mathrm{MoH})$. The $\mathrm{MoH}$ had no role in the design, analysis or writing of this article. Conflict of interest: None. Authorship: D.J.d.S. had a major role in the design of the study, the recruitment of the intervention sites, carrying out the study, data analysis and writing the article. S.S.W. was involved in the design of the study, the analysis and the writing of the article. M.C.C. took part in the design of the study, the writing of the article and the supervision of the whole study. Ethics of human subject participation: This study was approved by the institutional review board of the VU University Medical Centre (2005/ 209 and amendment 19 July 2007).

\section{Supplementary material}

To view supplementary material for this article, please visit http://dx.doi.org/10.1017/S1368980014000986

\section{References}

1. Cornel MC \& De Smit DJ (2011) The Dutch folate supplementation education programme:challenges in raising awareness. Gynaecol Forum 15, 21-25.

2. Zetstra-van der Woude AP, De Walle HEK \& De Jong-Van den Berg LTW (2012) Periconceptional folic acid use: still room to improve. Birth Defects Res Part A Clin Mol Teratol 94, 96-101.

3. Ajzen I \& Fishbein M (1980) Understanding Attitudes and Predicting Social Behavior. Englewood Cliffs, NJ: Prentice Hall.
4. Meijer WM, De Smit DJ, Jurgens R et al. (2004) Pharmacists' role in awareness about folic acid: a pilot on the process of introducing an intervention in pharmacy practice. Int $J$ Pharm Pract 12, 29-35.

5. de Walle HEK \& de Jong-van den Berg LT (2008) Ten years after the Dutch public health campaign on folic acid: the continuing challenge. Eur J Clin Pharmacol 64, 539-543.

6. Stoeldraijer L (2008) Jonge moeders stellen kinderen langer uit. Bevolkingstrends 4e Kwartaal, 27-27.

7. McNiff J \& Whitehead J (2002) Action Research. Principles and Practice, 2nd ed. New York: Routledge Falmer.

8. De Jong-Van den Berg LTW, De Smit DJ \& Meijer WM (2009) Preconceptionally self-reported use and intention to use of folic acid-supplements (rapid response). http:// www.bmj.com/rapid-response/2011/11/02/preconceptionallyself-reported-use-and-intention-use-folic-acid-supplemen (accessed October 2013).

9. Strecher VJ, De Vellis MB, Becker HM et al. (1986) The role of self-efficacy in achieving health behavior change. Health Educ Q 13, 73-91.

10. RIVM-Bilthoven (2013) Nationaal Kompas Volksgezondheid, versie 4.11. http://www.nationaalkompas.nl/bevolking/ scholing-en-opleiding/indeling-opleidingsniveau/ (accessed October 2013).

11. Altman DG (1991) Practical Statistics for Medical Research, 1st ed. London: Chapman \& Hall.

12. Sikkens JJ, van Eijsden M, Bonsel GJ et al. (2011) Validation of self-reported folic acid use in a multiethnic population: results of the Amsterdam Born Children and their Development study. Public Health Nutr 14, 2022-2028.

13. Meijer WM, De Smit DJ, Jurgens RA et al. (2005) Improved periconceptional use of folic acid after patient education in pharmacies: promising results of a pilot study. Int J Pharm Pract 13, 47-51.

14. Inskip HM, Crozier SR, Godfrey KM et al. (2009) Women's compliance with nutrition and lifestyle recommendations before pregnancy: general population cohort study. BMJ 338, b481.

15. Ray JG, Singh G \& Burrows RF (2004) Evidence for suboptimal use of periconceptional folic acid supplements globally. BJOG 111, 399-408.

16. TNO-PG (2003) Toegankelijkheid van de oudern-en kindzorg voor Marrokaanse en Turkse gezinnen. Leiden: TNO-PG.

17. Jentink J, Vries-Hoekstra NW, Jong-van den Berg LT et al. (2008) Economic evaluation of folic acid food fortification in The Netherlands. Eur J Public Health 18, 270-274.

18. Elsinga J, De Jong-Potjer LC, van der Pal-de Bruin KM et al. (2008) The effect of preconception counselling on lifestyle and other behaviour before and during pregnancy. Womens Health Issues 18, 6 Suppl., S117-S125.

19. Robbins JM, Cleves MA, Collins HB et al. (2005) Randomized trial of a physician-based intervention to increase the use of folic acid supplements among women. Am J Obstet Gynecol 192, 1126-1132. 